\title{
Origem e distribuição do nervo isquiático em fetos de javalis (Sus scrofa scrofa)
}

\author{
Luciana Pedrosa Iglesias ${ }^{1 *}$ \\ Frederico Ozanam Carneiro e Silva ${ }^{2}$ \\ Thalita Rocha Brito \\ ${ }^{1}$ PPG em Medicina Veterinária, na área de Saúde Animal \\ ${ }^{2}$ Faculdade de Medicina Veterinária \\ Universidade Federal de Uberlândia, Uberlândia - MG, Brasil \\ *Autor para correspondência \\ Rua Ceará, s/n, Bloco 2D, CEP 38400-902, Uberlândia - MG, Brasil \\ iglesias_1p@hotmail.com
}

Submetido em 16/05/2011

Aceito para publicação em 06/09/2011

\section{Resumo}

Para a análise da origem e distribuição do nervo isquiático, foram utilizados 22 fetos de javalis, obtidos do acervo do Laboratório de Pesquisa em Animais Silvestres (LAPAS) da Faculdade de Medicina Veterinária da Universidade Federal de Uberlândia (FAMEV-UFU). A artéria aorta descendente torácica foi canulada para injeção de formaldeído no sentido crânio-caudal, sendo que as peças foram mantidas submersas na referida solução por um período mínimo de $48 \mathrm{~h}$ antes do início das dissecações. O nervo isquiático originou-se dos ramos ventrais dos nervos espinhais L5 a S3 e emitiu ramos para os músculos glúteos médio e superficial, bíceps femoral, semimembranáceo, semitendíneo, piriforme, adutor e tensor da fáscia lata; o nervo cutâneo caudal da sura originou-se dos nervos isquiático ou fibular comum ou tibial.

Palavras-chave: Anatomia, Inervação, Plexo lombossacral, Suidae

\section{Abstract}

Origin and distribution of the sciatic nerve in wild boars fetuses (Sus scrofa scrofa). To analyze the origin and distribution of the sciatic nerve, 22 fetuses of wild boar were used, obtained from the collection of the Wild Animal Research Laboratory (LAPAS), of the College of Veterinary Medicine of Universidade Federal de Uberlândia (FAMEV-UFU). The thoracic descending aorta was cannulated for injection of formaldehyde in the craniocaudal direction, and the pieces were kept submerged in this solution for at least of $48 \mathrm{~h}$ before starting the dissections. The sciatic nerve originates from the ventral branches of spinal nerves L5 to S3 and it sent branches to the middle and superficial gluteal muscles, biceps femoris, semimembranosus, semitendinosus, piriformis, adductor and tensor fascia lata, the caudal cutaneous sural nerve originates from the sciatic or common fibular or tibial nerves.

Key words: Anatomy, Innervation, Lumbosacral plexus, Suidae 


\section{Introdução}

O javali europeu (Sus scrofa scrofa) pertence à família Suidae. É nativo do Norte da África, Europa e parte da Ásia, e sua carne é apreciada pelo homem há muito tempo, graças às propriedades organolépticas, pois apresenta baixos teores de gordura e colesterol e alto teor protéico. Quando comparada à de bovino, apresenta $85 \%$ menos calorias e $31 \%$ mais proteínas, despertando o interesse dos nutricionistas e consumidores, que exigem, cada vez mais, uma dieta balanceada e saudável (ANTUNES, 2001).

Sob o ponto de vista econômico, a exploração destes animais sempre se tornou pouco atraente devido à enorme dificuldade de se obter animais puros, sejam capturados vivos do seu ambiente natural ou oriundos de criatórios comerciais, e também pela maior lentidão no processo de ganho de peso quando comparados a outras espécies. No Brasil, existem diversos criadores que têm realizado o cruzamento de javalis machos com porcas comuns. A carne resultante, que tem sido batizada pelos próprios criadores como de "javaporco", é bastante diferente do javali puro, perdendo suas qualidades e aproximando-se mais às do porco. Em termos econômicos, essa prática também é bastante contestável, uma vez que não é possível voltarmos a obter javalis puros através de cruzamentos recorrentes (CATÁLOGO RURAL, 2008).

O nervo isquiático, o maior nervo do corpo deriva dos ramos ventrais da sexta raiz lombar e da primeira raiz sacral do tronco lombossacral. Normalmente possui uma quinta raiz lombar e pode receber um fascículo do segundo nervo sacral. Emerge através do forame isquiático maior como uma larga faixa plana que está unida, a princípio, ao nervo glúteo caudal passando ventral e caudalmente na parte ventral do ligamento sacrotuberal largo e na origem do músculo glúteo profundo. Na parte pélvica fornece pequenos ramos musculares para o músculo obturador interno, músculos gêmeos e para o músculo quadrado da coxa; à medida que dobra ventralmente, caudal a articulação do quadril, ele emite um grande ramo muscular que se divide para suprir o músculo semimembranáceo e as porções curtas do músculo bíceps da coxa e do músculo semitendinoso (SISSON; GROSSMAN, 1975).
De acordo com a descrição de Dyce et al., 2004 o nervo isquiático emerge através da conexão dos ramos ventrais do quinto e sexto nervos lombares e do primeiro e segundo nervos sacrais.

O referido nervo é formado pelos ramos ventrais do quinto e do sexto nervos lombares e do primeiro e segundo componentes sacrais do plexo lombossacral, com uma contribuição ocasional dos ramos ventrais do terceiro e quarto nervos lombares. Estas fibras convergem na extremidade caudal do primeiro segmento caudal e passam através do forame isquiático maior. É uma faixa plana situada na região glútea, no músculo glúteo profundo, que continua caudalmente sobre os músculos gêmeos, músculo quadrado da coxa e músculo adutor. Além dos nervos glúteo cranial e caudal, o nervo isquiático emite os seguintes ramos em sucessão: (1) Um ramo comunicante constante vai para o nervo pudendo, no limite caudal do forame isquiático maior. Ele corre ao longo da borda dorsal do músculo glúteo profundo, passando entre os vasos ilíacos internos e, desta forma, atinge o forame isquiático menor onde se une ao nervo pudendo. (2) Ao nível do trocânter maior do fêmur, ele libera um grande ramo muscular para as partes proximais do músculo glúteobíceps e músculo semitendinoso. (3) O nervo cutâneo caudal da coxa também inerva a pele imediatamente acima das inserções proximais do músculo glúteobíceps e o músculo semitendinoso, após correr entre os mesmos (nervos caudais das nádegas). (4) De sua superfície ventral ele emite ramos para os músculos gêmeos e músculo quadrado da coxa. (5) Ligeiramente distal, na região da coxa, ele emite um grande ramo muscular para o músculo glúteobíceps (parte média), músculo semitendinoso, músculo semimembranoso, músculo pectíneo e para o músculo adutor. (6) Outro ramo muscular é emitido para a parte distal do músculo glútebíceps. Algumas de suas fibras, após perfurarem este músculo, ramificam-se na fáscia e na pele da superfície lateral da coxa. A aparente divisão do nervo isquiático nos nervos fibular (peroneal comum) e tibial normalmente ocorre medialmente à coxa ou ligeiramente distal à mesma (GETTY, 1981).

Esse importante nervo do plexo pelvino foi estudado por Mihelic et al. (2004), que observaram que o nervo isquiático emergiu dos ramos ventrais do 
sexto e sétimo nervos lombares e do primeiro sacral em $33,33 \%$ de suínos com sete vértebras lombares. Isso pôde ser observado em menor número $(19,25 \%)$ nas amostras com seis vértebras lombares. Ocasionalmente, em $13,33 \%$, foi formado pelos ramos ventrais do sexto nervo lombar e do primeiro e segundo nervos sacrais em animais com seis vértebras lombares, já nos animais com sete vértebras lombares, o referido nervo emergiu da conexão dos ramos ventrais do sétimo nervo lombar e do primeiro e segundo sacrais em $7,40 \%$ dos casos. $\mathrm{O}$ nervo isquiático também se formou a partir da junção dos ramos do último nervo lombar e do primeiro sacral, e isso foi confirmado em $7,40 \%$ dos suínos analisados, sendo $4,44 \%$ nas amostras com seis vértebras lombares e em 2,56\% nas amostras com sete vértebras lombares. Do mesmo modo, ramos ventrais dos dois nervos finais lombares e do primeiro e segundo sacral se uniram para formar o nervo isquiático em $19,25 \%$ do total observado, dentre esses $12,59 \%$ eram referentes aos suínos com seis vértebras lombares, e $6,66 \%$ relativos às amostras com sete vértebras lombares.

O presente trabalho tem como objetivos aumentar o conhecimento e a fundamentação teórica sobre este importante nervo do plexo pélvico, em javalis. Dessa forma pretendemos contribuir com a anatomia comparativa e fornecer subsídios às áreas afins.

\section{Material e Métodos}

Foram dissecados 22 fetos de javalis Sus scrofa scrofa, obtidos do acervo do Laboratório de Pesquisa em Animais Silvestres (LAPAS) da FAMEV-UFU, entretanto algumas amostras apresentaram impossibilidade de observação e dissecação do membro pélvico. Assim sendo, em alguns casos totalizaram 21 animais analisados.

A descrição da metodologia utilizada foi repassada pelos pesquisadores do LAPAS, onde foi feita uma incisão na altura do nono espaço intercostal do antímero esquerdo para identificação e dissecação da aorta descendente torácica, que foi canulada para injeção no sentido crânio-caudal de formaldeído a $10 \%$. As peças foram mantidas submersas na referida solução por um período mínimo de $48 \mathrm{~h}$ antes do início da dissecação.
Efetuou-se uma incisão longitudinal na linha mediana ventral, desde a cartilagem do processo xifóide do osso esterno até a borda caudal da sínfise pélvica. No terço caudal da incisão longitudinal, foram realizadas duas incisões perpendiculares, sendo uma em cada antímero, até alcançar a linha mediana dorsal.

Desarticulou-se a sínfise pélvica por meio de uma secção longitudinal, atingindo a cavidade pélvica, da qual se afastou cranialmente os órgãos internos, inclusive terminações da aorta, veia cava caudal e do sistema nervoso autônomo. Para visualização das vértebras lombares, seccionou-se, longitudinalmente, a região da fossa paralombar até a borda caudal da última costela.

Os fragmentos de membros pélvicos, que tivemos acesso, foram preservados em solução aquosa de formol a $10 \%$. Após remoção de parte do tecido adiposo, rebateram-se os músculos psoas e quadrado lombar, para visualização dos ramos ventrais dos nervos espinhais lombares e sacrais de ambos os antímeros, que dão origem aos nervos isquiáticos direito e esquerdo. Para análise das distribuições dos ramos musculares dos nervos isquiáticos, em seus respectivos antímeros, foram rebatidas a pele e as fáscias subcutâneas da região lateral das coxas.

A descrição do trabalho foi feita de acordo com a International Committee on Veterinary Gross Anatomical Nomenclature (2005), e a análise estatística constou da avaliação dos dados, de forma descritiva, em termos de porcentagem.

\section{Resultados e Discussão}

Após a avaliação dos vinte e dois fetos de javalis Sus scrofa scrofa, constatou-se que todos os casos apresentavam seis vértebras lombares. Nos 22 espécimes a origem do nervo isquiático ocorreu dos ramos ventrais dos nervos espinhais de L5 a S3, em ambos os antímeros. Observou-se no antímero direito de um animal (4,55\%) que o nervo isquiático teve origem também em S3, e que em um outro feto $(4,55 \%)$, no antímero esquerdo, houve origem em L5, L6, S1 e S2. Mas em 77,27\% dos casos (17 amostras), foi encontrada origem em L5, L6 e S1 em ambos os antímeros (Tabela 1). 
TABELA 1: Origem do nervo isquiático nos antímeros direito (AD) e esquerdo (AE) de javalis (Sus scrofa scrofa). Uberlândia-MG, 2009.

\begin{tabular}{lcccc}
\hline Origem & $\begin{array}{c}\text { AE (n⿳⺈ de } \\
\text { animais) }\end{array}$ & $\begin{array}{c}\text { Total } \\
(\%)\end{array}$ & $\begin{array}{c}\text { AD }\left(\mathbf{n}^{\mathbf{0}} \text { de }\right. \\
\text { animais })\end{array}$ & $\begin{array}{c}\text { Total } \\
(\%)\end{array}$ \\
L5, L6 & 01 & $\mathbf{4 , 5 5}$ & - & - \\
L6, S1 & 02 & $\mathbf{9 , 0 9}$ & 04 & $\mathbf{1 8 , 1 8}$ \\
L5, L6, S1 & 17 & $\mathbf{7 7 , 2 7}$ & 17 & $\mathbf{7 7 , 2 7}$ \\
L5, L6, S1, S2 & 01 & $\mathbf{4 , 5 5}$ & - & - \\
L5, L6, S1, S2, S3 & - & - & 01 & $\mathbf{4 , 5 5}$ \\
\hline Total & 21 & $\mathbf{9 5 , 4 6}$ & 22 & $\mathbf{1 0 0}$ \\
\hline
\end{tabular}

O nervo isquiático emitiu ramos, nos dois antímeros, aos músculos glúteos médio e superficial, piriforme, semitendíneo, semimembranáceo, adutor, bíceps femoral e tensor da fáscia lata. O glúteo médio recebeu de dois a cinco ramos; o glúteo superficial de um a cinco ramos no antímero direito e de dois a cinco no esquerdo; o músculo piriforme recebeu dois ramos em $31,82 \%$ e $45,45 \%$ das amostras, nos antímeros esquerdo e direito respectivamente; o semitendíneo de dois a seis ramos em $100 \%$ dos exemplares nos dois antímeros; o músculo semimembranáceo apresentou três ramos em $50 \%$ dos fetos no antímero direito e $45,5 \%$ no esquerdo; $\mathrm{o}$ adutor de um a cinco ramos em ambos os antímeros em todos os javalis; o bíceps femoral recebeu de 7 a 15 e 7 a 14 ramos nos antímeros direito e esquerdo; e o tensor da fáscia lata recebeu de um a três ramos em todos os animais (100\%) nos dois antímeros estudados (Tabela 2).

De acordo com alguns autores consultados (SISSON; GROSSMAN, 1975; GETTY, 1981; DYCE et al., 2004) descreveram que o nervo isquiático emergiu dos ramos ventrais do quinto e sexto nervos lombares, e primeiro e segundo nervos sacrais, o que pôde ser observado em nossa pesquisa, em um único javali (4,55\%), no seu antímero esquerdo; já os demais variaram de L5 a S3, sendo 17 em L5, L6 e S1; e uma amostra (4,55\%) em L5, L6, S1, S2 e S3.

De acordo com Sisson e Grossman (1975), o nervo estudado forneceu ramos para os músculos obturador interno, gêmeos, quadrado da coxa, semimembranáceo, bíceps e semitendinoso. Getty (1981) descreveu ramificações para os músculos gluteobíceps, semitendinoso, gêmeos, quadrado da coxa, semimembranoso, pectíneo. Neste experimento, constatou-se que o nervo isquiático inervou os músculos glúteos médio e superficial, piriforme, semitendíneo, semimembranáceo, adutor, bíceps femoral e tensor da fáscia lata. O músculo gluteobíceps, referido pelos autores, foi escrito nos resultados como glúteo superficial e bíceps femoral (Tabela 2).

TABELA 2: Ramificações musculares do nervo isquiático nos antímeros direito (AD) e esquerdo (AE) em javalis (Sus scrofa scrofa). Uberlândia-MG, 2009.

\begin{tabular}{|c|c|c|c|c|}
\hline Músculo & $\begin{array}{l}\text { AE: } \mathrm{n}^{0} \text { ramos } \\
\text { (\% de animais) }\end{array}$ & $\begin{array}{l}\text { Total } \\
(\%)\end{array}$ & $\begin{array}{l}\text { AD: } n^{\circ} \text { ramos } \\
\text { (\% de animais) }\end{array}$ & $\begin{array}{l}\text { Total } \\
(\%)\end{array}$ \\
\hline Glúteo Médio & $\begin{array}{c}2(9,09 \%), 3(50 \%) \\
4(27,27 \%), 5(9,09 \%)\end{array}$ & 95,45 & $\begin{array}{c}2(9,09 \%), 3(45,45 \%), 4(36,36 \%), \\
5(9,09 \%)\end{array}$ & 100 \\
\hline Glúteo Superficial & $\begin{array}{l}2(9,09 \%), 3(40,91 \%), \\
4(27,27 \%), 5(9,09 \%)\end{array}$ & 86,36 & $\begin{array}{c}1(4,55 \%), 2(22,73 \%), 3(36,36 \%) \\
4(22,73 \%), 5(9,09 \%)\end{array}$ & 95,46 \\
\hline Piriforme & $\begin{array}{l}1(22,73 \%), 2(31,82 \%), \\
3(27,27 \%), 4(13,64 \%)\end{array}$ & 95,46 & $\begin{array}{c}1(31,82 \%), 2(45,45 \%), 3(13,64 \%) \\
4(4,55 \%), 5(4,55 \%)\end{array}$ & 100 \\
\hline Semitendíneo & $\begin{array}{c}2(4,55 \%), 3(22,73 \%), 4(27,27 \%), \\
5(27,27 \%), 6(13,64 \%)\end{array}$ & 95,46 & $\begin{array}{c}2(18,18 \%), 3(27,27 \%) \\
4(31,82 \%), 5(9,09 \%), 6(13,64 \%)\end{array}$ & 100 \\
\hline Semimembranáceo & $\begin{array}{c}1(4,55 \%), 2(31,82 \%), 3(45,45 \%) \\
4(4,55 \%), 5(4,55 \%), 6(4,55 \%)\end{array}$ & 95,47 & $\begin{array}{c}2(22,73 \%), 3(50 \%), 4(13,64 \%), \\
5(4,55 \%), 6(4,55 \%), 7(4,55 \%)\end{array}$ & 100 \\
\hline Adutor & $\begin{array}{c}1(4,55 \%), 2(22,73 \%), 3(27,27 \%) \\
4(27,27 \%), 5(13,64 \%)\end{array}$ & 95,46 & $\begin{array}{c}1(4,55 \%), 2(22,73 \%), 3(50 \%) \\
4(13,64 \%), 5(9,09 \%)\end{array}$ & 100 \\
\hline Bíceps Femoral & $\begin{array}{c}7(4,55 \%), 8(9,09 \%), 9(22,73 \%), \\
10(27,27 \%), 11(13,64 \%), 12(4,55 \%), \\
13(4,55 \%), 14(4,55 \%), 15(4,55 \%)\end{array}$ & 95,48 & $\begin{array}{c}7(9,09 \%), 8(9,09 \%), 9(22,73 \%) \\
10(22,73 \%), 11(9,09 \%), 12(13,64 \%), \\
13(4,55 \%), 14(9,09 \%)\end{array}$ & 100 \\
\hline $\begin{array}{l}\text { Tensor da Fáscia } \\
\text { Lata }\end{array}$ & $1(59,09 \%), 2(27,27 \%), 3(4,55 \%)$ & 90,91 & $1(22,73 \%), 2(54,55 \%), 3(4,55 \%)$ & 81,83 \\
\hline
\end{tabular}


Notou-se ainda que o nervo cutâneo caudal da sura originou-se em 10 animais $(45,45 \%)$ do nervo fibular comum, no antímero esquerdo, e em oito amostras no direito; em cinco fetos $(22,73 \%)$, teve origem no nervo tibial no antímero esquerdo, e em oito $(36,36 \%)$ no direito; em seis $(27,27 \%)$ javalis, o cutâneo originou-se do nervo isquiático no antímero esquerdo, e cinco $(22,73 \%)$ no direito (Tabela 3$)$. O referido nervo recebe essa nomenclatura de acordo com a International Committee on Veterinary Gross Anatomical Nomenclature (2005), mas é encontrado na literatura como nervo cutâneo caudal da coxa por Getty (1981).

TABELA 3: Origem do nervo cutâneo caudal da sura nos antímeros direito (AD) e esquerdo (AE) de 21 javalis (Sus scrofa scrofa). Uberlândia-MG, 2009.

\begin{tabular}{lcccc}
\hline Origem & $\begin{array}{c}\text { AE (no de } \\
\text { animais) }\end{array}$ & $\begin{array}{c}\text { Total } \\
\mathbf{( \% )}\end{array}$ & $\begin{array}{c}\text { AD (no de } \\
\text { animais) }^{-}\end{array}$ & $\begin{array}{c}\text { Total } \\
\mathbf{( \% )}\end{array}$ \\
Tibial & 05 & $\mathbf{2 2 , 7 3}$ & 08 & $\mathbf{3 6 , 3 6}$ \\
Fibular & 10 & $\mathbf{4 5 , 4 5}$ & 08 & $\mathbf{3 6 , 3 6}$ \\
Comum & & & & $\mathbf{2 2 , 7 3}$ \\
Isquiático & 06 & $\mathbf{2 7 , 2 7}$ & 05 & $\mathbf{9 5 , 4 5}$ \\
\hline Total & 21 & $\mathbf{9 5 , 4 7}$ & 21 & \\
\hline
\end{tabular}

O número de animais de antímero esquerdo analisado foi de 21 (Tabelas 1 e 3), devido à impossibilidade de análise e dissecação da peça.

Dessa forma, podemos perceber a importância do plexo lombossacral em animais, ainda que existam poucos estudos científicos no que diz respeito ao nervo isquiático em javalis.
A partir dos resultados, conclui-se que o nervo isquiático origina-se dos ramos ventrais dos nervos espinhais de L5 a S3, emitindo ramos para os músculos glúteos médio e superficial, bíceps femoral, semimembranáceo, semitendíneo, piriforme, adutor e tensor da fáscia lata. Além disso, o nervo cutâneo caudal da sura pode se originar dos nervos fibular comum, ou tibial, ou isquiático.

\section{Referências}

ANTUNES, R. Comida de gaulês? Suinocultura Industrial, Itu, v. 151, p. 24-27, 2001.

CATÁLOGO RURAL. Javali/Enciclopédia. 2008. Disponível em: $<$ http://www.agrov.com/animais/peq_ani/javali.htm $>$. Acesso em: 6 jun. 2008.

DYCE, K.; SACK, W.; WENSING, D. Textbook of veterinary anatomy. Philadelphia: W. B. Saunders Company, 1987. 834 p.

GETTY, R. Sisson/Grossman: anatomia dos animais domésticos. 5. ed. Rio de Janeiro: Interamericana, 1981. 2000 p.

INTERNATIONAL COMMITTEE ON VETERINARY GROSS ANATOMICAL NOMENCLATURE. Nomina anatômica veterinária. 5 ed. Knoxville: World Association on Veterinary Anatomist, 2005. 190 p.

MIHELIC,D.; V.GJURCEVIC-KANTURA, S.; MARKOVINOVIC, A.; DAMJANOVIC, T.; TRBOJEVIC-VUKICEVIC. Variations of formation of $\mathrm{n}$. femoralis, $\mathrm{n}$. obturatorius and $\mathrm{n}$. ischiadicus in pigs. Veterinarski Arhiv, Zagreb, v. 74, p. 261-270, 2004.

SISSON, S.; GROSSMAN, J. D. Anatomia de los animales domésticos. 4. ed. Barcelona: Salvat, 1975. 2095 p. 